\title{
THE EXPERIMENTAL IDENTIFICATION OF THE DYNAMIC COEFFICIENTS OF TWO HYDRODYNAMIC JOURNAL BEARINGS OPERATING AT CONSTANT ROTATIONAL SPEED AND UNDER NONLINEAR CONDITIONS
}

\author{
Łukasz Breńkacz ${ }^{1)}$, PhD, Eng. \\ Grzegorz Żywica ${ }^{1)}$, PhD, Eng. \\ Marta Drosińska-Komor ${ }^{2)}$, MSc \\ 1) Department of Turbine Dynamics and Diagnostics, Institute of Fluid Flow Machinery, Polish Academy of Sciences \\ 2) Gdańsk University of Technology, Faculty of Ocean Engineering and Ship Technology, Poland
}

\begin{abstract}
Hydrodynamic bearings are commonly used in ship propulsion systems. Typically, they are calculated using numerical or experimental methods. This paper presents an experimental study through which it has been possible to estimate 24 dynamic coefficients of two hydrodynamic slide bearings operating under nonlinear conditions. During the investigation, bearing mass coefficients are identified by means of a newly developed algorithm. An impact hammer was used to excite vibration of the shaft. The approximation by means of the least squares method was applied to determine bearing dynamic coefficients. Based on the performed research, the four (i.e. two main and two crosscoupled) coefficients of stiffness, damping and mass for each bearing were obtained. The mass coefficients add up to the complex shaft weight. These values are not required for modeling dynamics of the machine because the rotor mass is usually known, however, they may serve as a good indicator to validate the correctness of the stiffness and damping coefficients determined.

Additionally, the experimental research procedure was described. The signals of displacements in the bearings and the excitation forces used for determination of the bearing dynamic coefficients were shown. The study discussed in this article is about a rotor supported by two hydrodynamic bearings operating in a nonlinear manner. On the basis of computations, the results of bearing dynamic coefficients were presented for a selected speed.
\end{abstract}

Keywords: bearing dynamic coefficients, experimental research, nonlinear coefficients, impact excitation, hydrodynamic bearing

\section{INTRODUCTION}

Hydrodynamic bearings are integral parts of the vast majority of propulsion systems installed on modern ships. Article [10], provides one example of how complex such a system can be and how its efficiency can be increased using a combination of different devices, i.e. Diesel engine, gas turbine and steam turbine. The contemporary ship power plant is presented in article [14] and operational and economic analysis of some parts of the steam turbine power plant is discussed in article [3]. A summary of losses and energy efficiency of drive motors is presented in paper [18]. Descriptions of hydrodynamic bearings used in shipbuilding industry can be found in papers $[16,17]$. The analyses presented in these papers concern various materials used in bearing constructions and load-carrying capacity. Values of stiffness and damping coefficients of hydrodynamic bearings are the most important from the point of view of dynamical performance $[12,13]$. Because of many difficulties in numerical modelling, many experimental methods for determination of their values have been proposed [9,21]. Experimental investigations were performed with different types of bearings. The paper [8] presents the identification of dynamic coefficients of a hybrid gas bearing that has a sophisticated and robust construction with a complex structure of the foils. The literature study showed that an experimental determination of stiffness and damping bearing characteristics is conducted not just for radial bearings but for thrust bearings as well. 
The experimental identification of stiffness and damping characteristics for an axial foil bearing has been dealt with in detail in article [1]. Bearing dynamic coefficients change along with the rotational speed $[15,23]$.

The article presents the continuation of research described in articles $[4,5]$. The measurement methodology has already been described in detail in these articles. This article focuses on the results from experimental studies. The calculation algorithm for experimental determination of stiffness, damping and mass coefficients of two hydrodynamic bearings using an impulse excitation of the rotating shaft was developed and could be found in article [4]. It is based on conventional linear modelling methods and the least squares method for approximation purposes. When it comes to analyzing systems the operations of which are nonlinear (like in the case of the test rig analyzed in this article), calculations are performed with a certain approximation - as if the response signal would originate from a linearly operating system. The results presented there were calculated using numerically generated signals. The rotor was supported by two hydrodynamic slide bearings. During its operation at constant rotational speed, the shaft was excited by an appropriate force acting between the bearings. The modelled excitation corresponds very closely to the excitation which was applied by an impulse hammer during the experimental research. The displacements of the bearing journals were registered following the application of the excitation to the central part of the shaft. In the next step, the stable operation signal is subtracted from the signal registered after the excitation. As a result, a fading signal which is sinusoidal in shape was obtained. The stiffness, damping and mass coefficients of the rotor - bearings system were determined on its basis and on the basis of excitation force signal.

In numerical simulations dealing with bearings, their stiffness and damping coefficients must be known. The coefficients identification requires either carrying out additional computations or performing experimental research. The computational method discussed herein allows us to obtain not only stiffness and damping coefficients but also mass coefficients - and it does that in one calculation step. The mass coefficients are broadly equivalent to the shaft mass. Calculated values of mass coefficients can be easily verified because the shaft mass is known. The experimental methods for identification of bearing dynamic coefficients are prone to a large amount of measurement errors. Upon verification of mass coefficients, results obtained from an experimental research can be tested for correctness in a swift and straightforward manner. The calculations of added mass coefficients of the skewed marine propellers are shown in publication [22]. The three-dimensional boundary element method (BEM) was developed to predict the propeller added mass and moment of inertia coefficients. The values of the added mass coefficients were predicted based both on geometric and flow parameters of the analyzed propeller.

Paper [6] describes an experimental study which was conducted on a test rig to determine dynamic performance characteristics of a tilting-pad journal bearing. The next publication [7] shows that by changing operating parameters of the rotating system or the measuring method the authors obtained different values of the bearing dynamic coefficients.

Article [5] concerns the sensitivity analysis of an experimental method for identification of dynamic coefficients of the hydrodynamic bearings. The analyses were conducted on the basis of signals generated by numerical models. The main parameters of concern were as follows: rotor geometry, material properties, position and angle of the measuring sensors as well as location and angle of the vibration excitation applied by an impact hammer made by PCB Piezotronics (model $086 \mathrm{C} 03$ with a metal tip). As the numerical model allows all input data to be changed, it is possible to compare the calculated and set dynamic coefficients of the hydrodynamic bearings. It turned out that the theoretical accuracy of the coefficients determination is very high. The sensitivity analysis proved to be very helpful in orienting the attention towards the aspects that are especially relevant in the calculation process. Furthermore, it indicated the need for some adjustments, by the introduction of which the numerical model started to generate correct results.

\section{BASIC TECHNICAL CHARACTERISTICS OF THE TEST RIG AND THE MEASUREMENT RESULTS}

The test rig for testing small rotors was built in order to be able to conduct research on rotor - bearings systems and to analyze defects, such as bearing damage, rotor unbalance, shaft misalignment, etc. The photo of the test rig is presented in Fig. 1. Its weight - without the supporting structure - is approximately $60 \mathrm{~kg}$.

The length of the test rig is $1.25 \mathrm{~m}$, and its width and height are $0.36 \mathrm{~m}$ and $0.65 \mathrm{~m}$, respectively. The axes of the coordinate system used during the experimental research are shown in the top left-hand corner of Fig. 1. The test rig rests on a $13 \mathrm{~mm}$ steel plate with two channel bars attached to it that are equipped with rubber feet that allow adjusting the height of the plate and its levelling. The rotor shaft was supported by two bearings. The system was driven by a three-phase motor with a maximum speed of $3450 \mathrm{rpm}$. The motor speed was adjusted by means of a frequency converter with capacity of $1.5 \mathrm{~kW}$. The motor was connected to a gear that increases the speed with a gear ratio 3.5:1. The presence of the inverter allows varying the motor speed up to $12,000 \mathrm{rpm}$. The gear is connected to the rotor shaft using a permanent coupling. The coupling diameter is $50 \mathrm{~mm}$ and its length is $60 \mathrm{~mm}$. The oil-lubricated bearing system was equipped with a pump. During the experimental tests, the oil pressure was $0.16 \mathrm{MPa}$. Displacements of the rotor were measured using eddy current displacement transducers (model CWY-DO-501A) having a sensitivity of about $4 \mathrm{mV} / \mu \mathrm{m}$. 


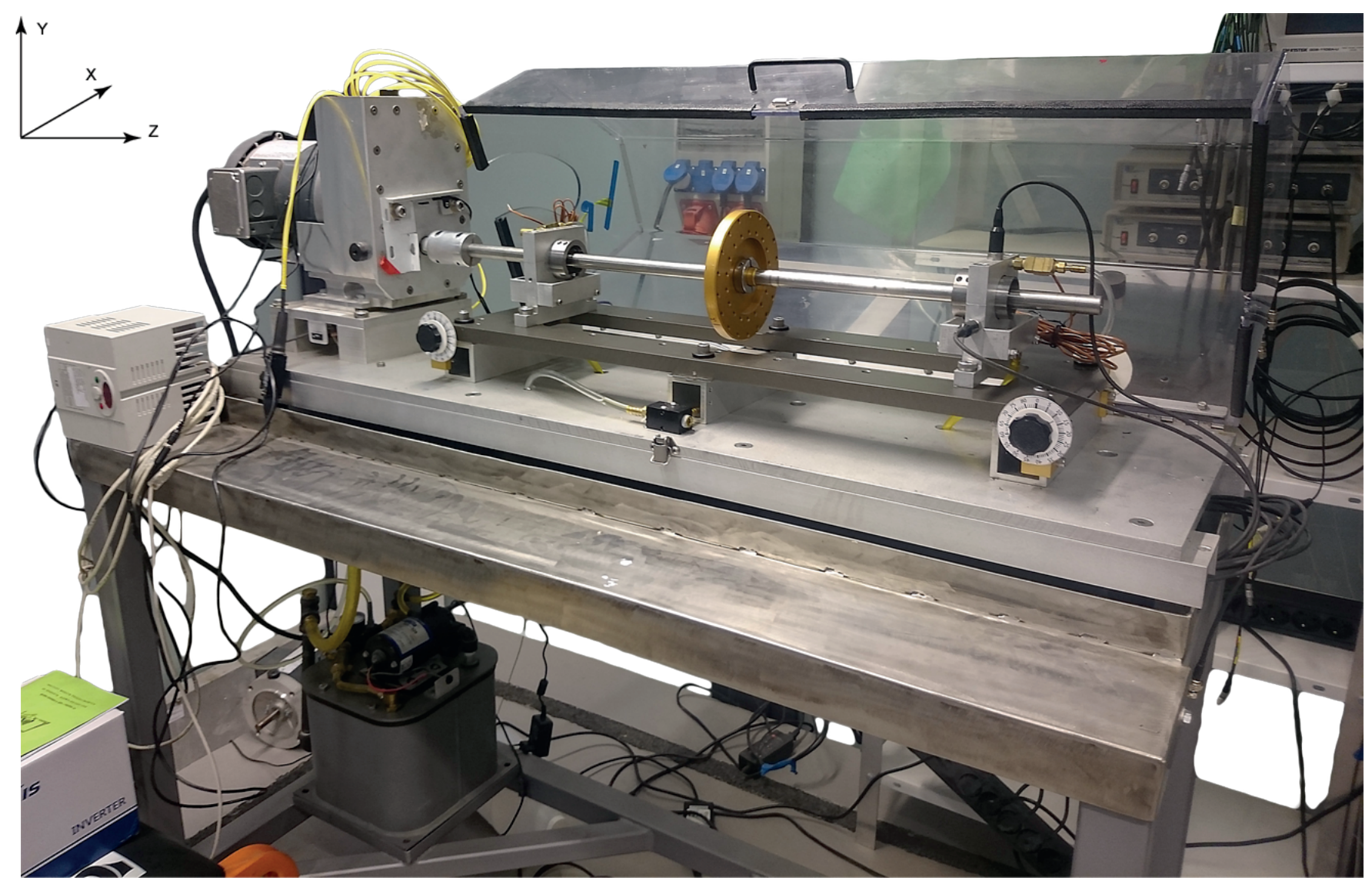

Fig. 1. Test rig

The vibration trajectories for bearing no. 2 (the one that lies further away from the coupling, respectively) are presented in Fig. 3. The graph represents 12 rotor revolutions at the

The tested rotor has a length of $920 \mathrm{~mm}$. The distance between the coupling and the first bearing support was $170 \mathrm{~mm}$. The rotor was mounted in two bearing supports. The distance between the supports was $580 \mathrm{~mm}$. The rotor disc is equidistant to each bearing supports. The rotor diameter is $19.02 \mathrm{~mm}$ and the rotor disc diameter is $152.4 \mathrm{~mm}$. The excitations were applied using an impact hammer at the point that is shifted $30 \mathrm{~mm}$ from the rotor disc's midpoint. For safety reasons, the rotor - bearings system was equipped with a lockable casing made of hard transparent plastic.

The rotor was supported by two hydrodynamic bearings (Fig. 2) with the same geometries. The radial bearing clearance is $76 \mu \mathrm{m}$ and the bearing length is $12.6 \mathrm{~mm}$. Every bearing has two supply ports located on both sides of the shaft. The supply ports have a diameter of $2.54 \mathrm{~mm}$. The oil supply pressure was $0.16 \mathrm{MPa}$. The viscosity grade of the lubricating oil is consistent with ISO 13 recommendations.

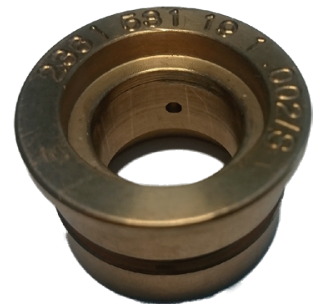

Fig. 2. The hydrodynamic bearing rotational speed of 4,500 rpm. Signals are filtered using a band-pass filter which rejects frequencies below $1 / 3 \mathrm{X}$ and above $3 \mathrm{X}$ (3rd harmonic).

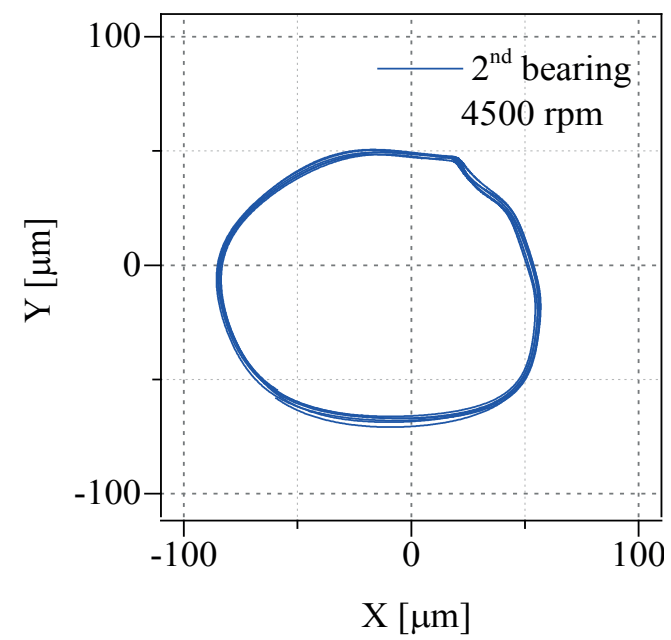

Fig. 3. Vibration trajectories at 4,500 rpm obtained for the bearing situated further away from the coupling

Despite the precise alignment of the shaft ends, the rigid coupling had a big impact on the vibration trajectories of the first bearing. Fig. 4 clearly indicates a phenomenon called „whirl”. [10]. It should be stressed that dynamics of the 
rotating system are affected not only by the coupling and bearings but also by the whole supporting structure [2]. There are also other elements (such as twisted blades) that have an impact on vibrations of the entire system since they influence vibration trajectories of the bearing journals [11].

a)

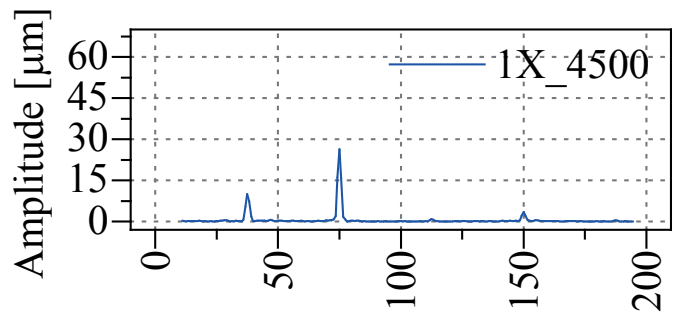

Frequency $[\mathrm{Hz}]$

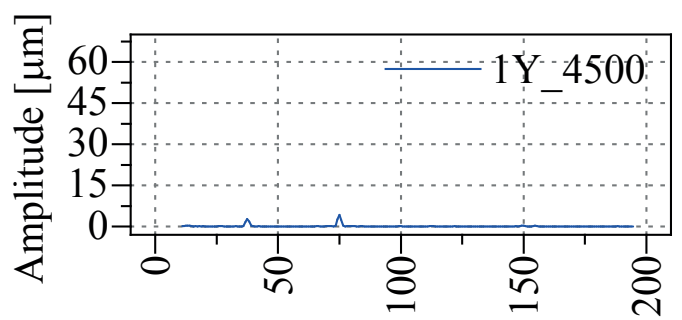

b)

Frequency $[\mathrm{Hz}]$

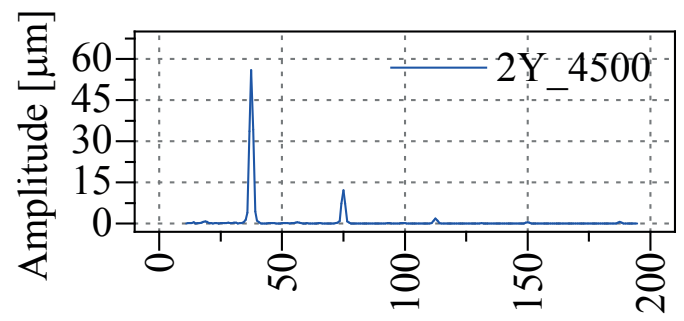

c)

Frequency $[\mathrm{Hz}]$

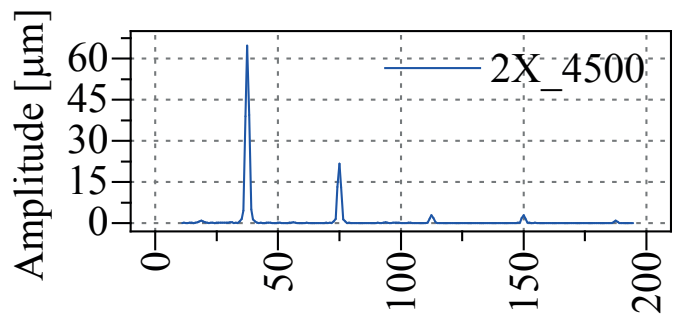

d)

Frequency $[\mathrm{Hz}]$

Fig. 4. The FFT spectra presenting the bearing journal displacements for the bearing no. 1 (two top graphs) and no. 2 (two bottom graphs)

Figure 3 presents the FFT spectra showing the bearing journal displacements for both bearings along the $\mathrm{X}$ and $\mathrm{Y}$ axes. These axes correspond to the axes of the coordinate system already given in Fig. 1. The denotation of " $1 \mathrm{X}$ " refers to the displacement measurement of bearing no.1 (the one that lies closer to the coupling) in the $\mathrm{x}$-direction (a horizontal direction). Likewise, the denotation of " $2 \mathrm{Y}$ " indicates the measurement of bearing no. 2 in the y-direction (a vertical direction). The measurements were made at the rotational speed of 4,500 rpm that corresponds to the frequency of $75 \mathrm{~Hz}$. This value can be observed on the graphs as the second component (counting from the left). Besides the first harmonic (1X), also the $1 / 2$ subharmonic (having the frequency of $37.5 \mathrm{~Hz}$ ) is present on the graph denoted " $1 \mathrm{X}$ ". The $1 / 2$ subharmonic dominates the FFT spectra regarding bearing no. 2 . This is clearly the indication of the unstable operation of the bearings.

\section{CALCULATION OF DYNAMIC COEFFICIENTS OF THE HYDRODYNAMIC BEARINGS}

The calculation diagram of the experimental determination of bearing dynamic coefficients is presented in Fig. 5. In the first step, the necessary experimental research is carried out. The rotor shaft surface (situated at a distance of $30 \mathrm{~mm}$ from the disc) is hit in a horizontal direction (X) with an impact hammer when the rotor rotates at constant speed. This action was repeated around a dozen times within 40 seconds. Then, the measurement is performed in the same way with the only difference being that hitting the shaft is performed in a vertical direction (Y). In the second step, the reference signal (corresponding to the stable operation of the rotor) is subtracted from the signal registered after the excitation. This operation was carried out using the computer program called "Signal", created for this purpose. The third step consists in centering values of the signal corresponding to an excitation force and omitting the values related to the main component. The signals thus obtained are subjected to an FFT (Fast Fourier Transform) analysis [11]. The spectral components received after the centering process are analyzed in a frequency domain. The matrixes A, Z and I are then created. Z matrix contains bearings' dynamic coefficients that are to be identified, I is an identity matrix and A matrix consists of input signals needed for computations. These input signals relate to excitation forces and measured responses of the mechanical system.

Measuring the necessary signals: signal of exciting force, system response signal
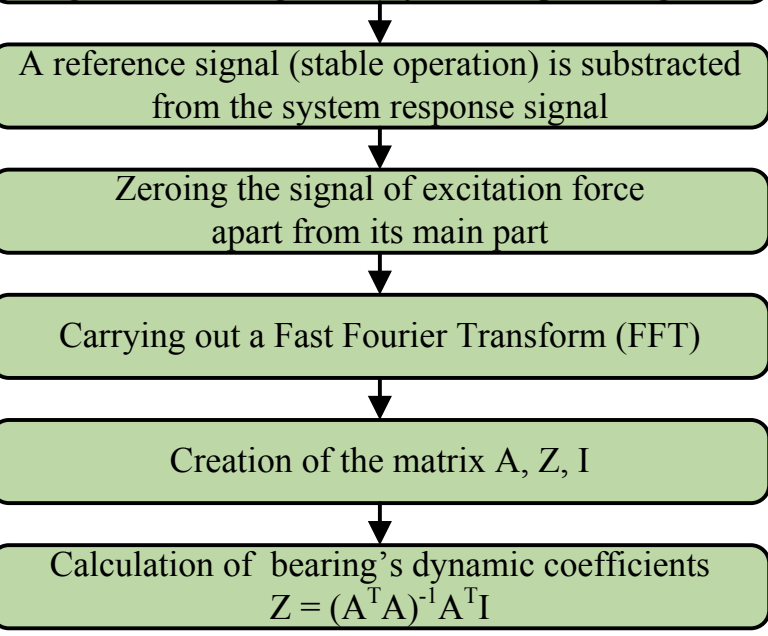

Fig. 5. Calculation procedure for bearing dynamic coefficients 
The detailed description of the experimental method for identifying bearing dynamic coefficients is given in paper [4]. Computations are performed with signals represented in a frequency domain. The dynamic coefficients of the bearings are estimated on the basis of the resonance range. The frequencies of the natural vibrations of fluid-flow machinery vary with rotational speed. During the analysis of dynamic coefficients of the bearings, the resonance range of the rotor should be taken into account for each rotational speed. The coefficients are calculated using the least squares method.

If a force applied using the impact hammer is located in the middle part of the rotor, it should be divided by 2 and the obtained value will be the value of the excitation force corresponding to a single bearing. In the event when the excitation is applied at a point that is not equidistant from each of the bearings, the excitation force have to be distributed between the bearings proportionately to the distances between them.

a)

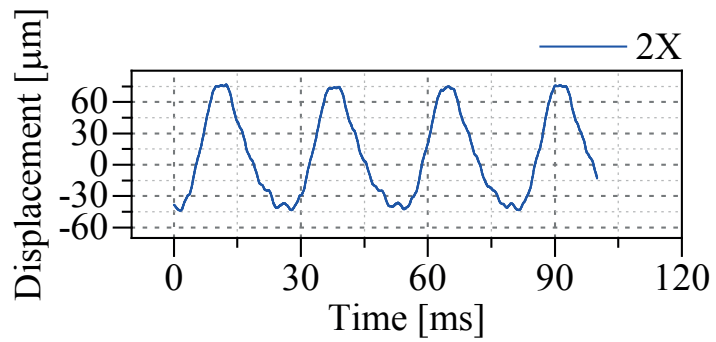

b)

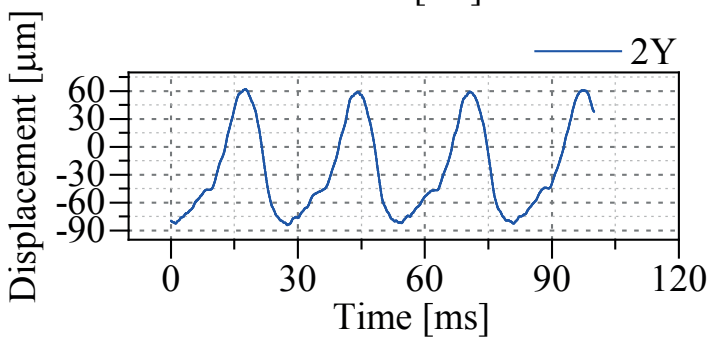

c)

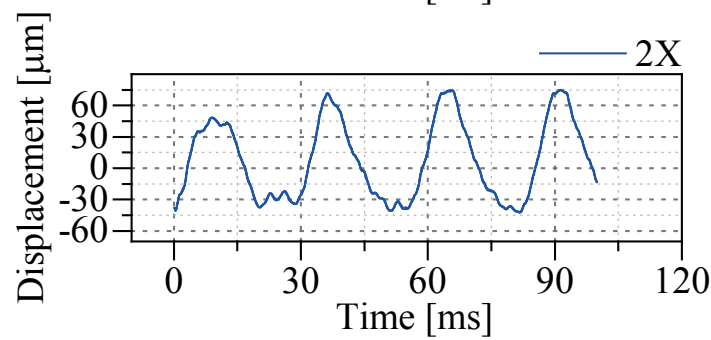

d)

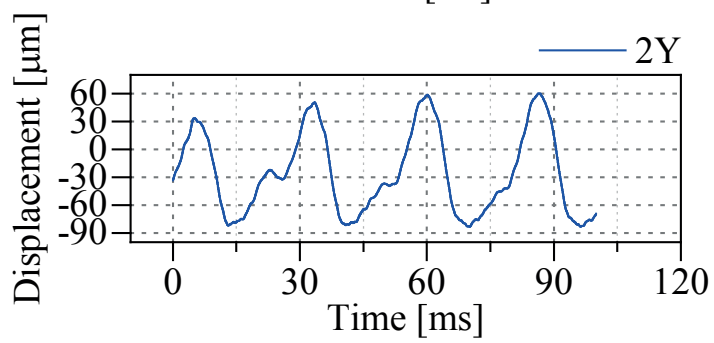

Fig. 6. Stable operation of the bearing no. 2 at 4,500 rpm (the two upper graphs) and the signal obtained after the excitation had been applied (the two lower graphs). The graphs denoted by a) and c) present the signals along the $X$ direction, while the ones denoted by $b$ ) and $d$ ) the signals along the $Y$ direction
Fig. 6 presents the signals measured during the experimental research. The two upper graphs show the displacements of bearing no. 2 during its stable operation, in the $\mathrm{X}$ and $\mathrm{Y}$ directions (respectively on the left and right-hand sides). The journal displacements shown on the lower graphs were registered immediately after applying the excitation to the test system using an impact hammer. As we can observe, there is increase or decrease in the vibration amplitude depending on the rotor position. The differences between the lower and upper signals were the basis for carrying out the calculations of dynamic coefficients of the hydrodynamic bearings. The signal resulting from the subtraction of the stable operation signal from the signal registered after the excitation is presented in Fig. 8 as a black curve. This signal relates bearing no. 2 and the X-direction. On its basis, the bearing dynamic coefficients were determined.

\section{CALCULATION RESULTS}

The calculations of stiffness, damping and mass coefficients were performed on the basis of the measured displacements of bearing journals and the excitation force signal as well. The calculation process is illustrated in Fig. 5. Table 1 presents the resulting values of stiffness, damping and mass coefficients for the rotor - bearings system. The results were obtained using six data sets. The table lists the average values and their respective standard deviations.

The results obtained for the bearing that lies closer to the coupling are characterized by higher standard deviations. This fact can be explained by the significant impact of the rigid coupling on the bearing operation. This impact could be considerably reduced by replacing the coupling by a more flexible one. During analysis of the results, only the results obtained for the bearing situated at the free end of the rotor's shaft should be considered as reference values.

Notwithstanding the fact that both hydrodynamic bearings have the same geometries, different values of dynamic coefficients have been obtained for the two bearings. Higher standard deviations in the results for bearing no. 1 (in comparison to bearing no. 2) imply that there is a discrepancy between the results obtained for each bearing. Given the highly nonlinear nature of the test system, one could have expected such high standard deviations. The experimental results concerning this type of systems have very little repeatability, which was reflected in the results presented herein. The values of main coefficients (denoted by $\mathrm{xx}$ and $\mathrm{yy}$ ) have lower standard deviations than the crosscoupled coefficients (denoted by xy and yx). Some crosscoupled stiffness, damping and mass coefficients have higher standard deviations than their average values.

The values of errors for dynamic coefficients of hydrodynamic bearings calculated using different experimental methods can be as high as 60 percent - in some cases, even an order of magnitude. A summary of the values of errors obtained for ten or so cases described in the literature was prepared by T.W. Dimond et al. and 
presented in paper [9]damping, and mass terms, related to machine vibrations. Detailed numerical values of the bearing dynamic characteristics are necessary for proper design and operation of rotating machinery. The methods of the identification of fluid film journal bearing static and dynamic characteristics, particularly the bearing stiffness, damping, and mass coefficients, from measured data, obtained from different measurement systems, is reviewed. Many bearing tests have been performed to validate a number of different theoretical models, including the classical Reynolds isoviscous model. More advanced bearing models include the thermohydrodynamic (THD. By comparing the obtained standard deviation values with the ones described in the literature, it has been established that our results are satisfactory.

Tab. 1. The values of stiffness, damping and mass coefficients during the operation at 4,500 rpm

\begin{tabular}{|c|c|c|}
\hline $\begin{array}{c}\text { dynamic } \\
\text { coefficients }\end{array}$ & $\begin{array}{c}\text { bearing that lies further } \\
\text { away from the coupling }\end{array}$ & $\begin{array}{c}\text { bearing that lies closer } \\
\text { to the coupling }\end{array}$ \\
\hline $\mathrm{k}_{\mathrm{xx}}[\mathrm{N} / \mathrm{m}]$ & $9733 \pm 8312$ & $43453 \pm 18308$ \\
\hline $\mathrm{k}_{\mathrm{xy}}[\mathrm{N} / \mathrm{m}]$ & $-11892 \pm 16333$ & $46104 \pm 48399$ \\
\hline $\mathrm{k}_{\mathrm{yx}}[\mathrm{N} / \mathrm{m}]$ & $20724 \pm 17593$ & $24824 \pm 28357$ \\
\hline $\mathrm{k}_{\mathrm{yy}}[\mathrm{N} / \mathrm{m}]$ & $14733 \pm 14107$ & $87802 \pm 64875$ \\
\hline$c_{x x}[\mathrm{Ns} / \mathrm{m}]$ & $25 \pm 15$ & $25 \pm 19$ \\
\hline$c_{x y}[\mathrm{Ns} / \mathrm{m}]$ & $-5 \pm 22$ & $22 \pm 37$ \\
\hline$c_{y x}[\mathrm{Ns} / \mathrm{m}]$ & $15 \pm 11$ & $-54 \pm 36$ \\
\hline$c_{y y}[\mathrm{Ns} / \mathrm{m}]$ & $19 \pm 17$ & $17 \pm 25$ \\
\hline $\mathrm{m}_{\mathrm{xx}}[\mathrm{kg}]$ & $0.11 \pm 0.10$ & $0.52 \pm 0.4$ \\
\hline $\mathrm{m}_{\mathrm{xy}}[\mathrm{kg}]$ & $-0.13 \pm 0.23$ & $0.66 \pm 0.85$ \\
\hline $\mathrm{m}_{\mathrm{yx}}[\mathrm{kg}]$ & $0.22 \pm 0.40$ & $0.58 \pm 0.55$ \\
\hline $\mathrm{m}_{\mathrm{yy}}[\mathrm{kgg}]$ & $0.16 \pm 0.13$ & $1.31 \pm 1.09$ \\
\hline
\end{tabular}

\section{VERIFICATION OF THE RESULTS}

For verification of the experimental results, the model of the test system was prepared using Abaqus 6.14-2. The model consisted of a concentrated mass point with one degree of freedom and an elastic-damping element (Fig. 7). The method used for the verification of results is the same as the one proposed by Qiu and Tieu [19]. The force value acting during the experimental research as well as the stiffness and damping characteristics determined on the basis of experimental studies were incorporated into this numerical model. The calculated displacement of the concentrated mass point resulting from a pulse force applied to it was compared with the system response measured during the experimental research.

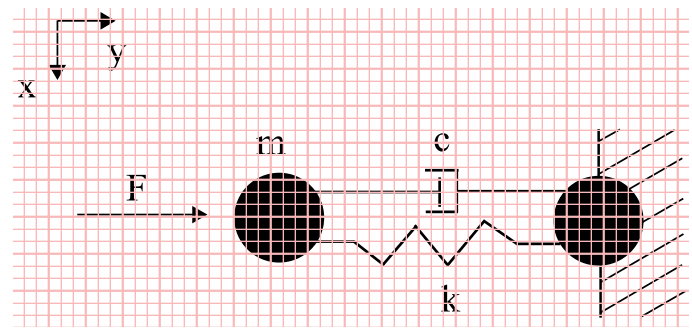

Fig. 7. Simplified schematic diagram of the test system consisting of a concentrated mass and an elastic-damping element

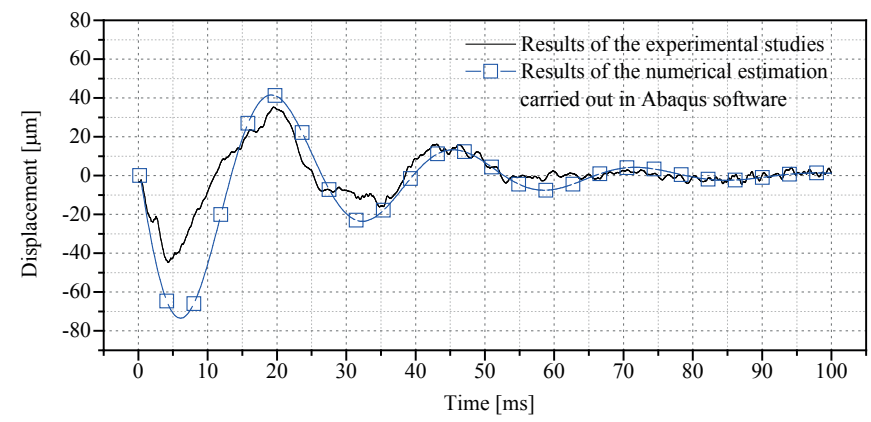

Fig. 8. Dynamic response coming from the real system and the numerical model (this model takes into account the experimentally determined stiffness and damping coefficients)

Both components in the model lie in the same plane. The first component is fully constrained (i.e. all degrees of freedom are removed), while the second component has only one degree of freedom left, namely, motion in the $\mathrm{Y}$ direction. The mass attributed to the concentrated mass point was $2.35 \mathrm{~kg}$, representing half of the rotor mass. The two components are connected with one another by an elastic-damping element. The stiffness of this element was $8,700 \mathrm{Nm}$, and its damping was $51 \mathrm{Nm} / \mathrm{s}$. These are not the average values given in Tab. 1, but the values corresponding to one of the calculation cases carried out at the rotational speed of 4,500 rpm.

The value of the excitation force corresponded to half of the value measured during the experimental research. Its value for the consecutive time steps was $\mathrm{F}=[0,0,11,59,49,44$, $10,0] \mathrm{N}$. During the analysis, the time step corresponded to the frequency of the measurements. The duration of the excitation force was approximately $0.1 \mathrm{~ms}$ and was the same as that in the experimental test.

The calculation results showing the displacements of the concentrated mass point with one degree of freedom are presented in Fig. 8 (blue line with square data markers). Fig. 8 also shows the signal measured during the experimental research (black line). The comparison of the two displacement curves leads to the conclusion that the stiffness and damping coefficients incorporated into the numerical model reflect the essential characteristics of the real object in a reliable manner. In order to ensure that results are reliable, a verification should be performed for each direction. Movement of the bearing journal is described by 4 stiffness coefficients and 4 damping coefficients which have an influence on the system operation at the same time. For verification purposes, they can be considered as separate values. 


\section{SUMMARY AND CONCLUSIONS}

The object of this study is a rotor supported by two hydrodynamic bearings. This system has a strongly nonlinear nature, e.g. quite a number of large-sized vibration trajectories as well as sub-and super-harmonic vibration components were observed. The research methodology used was developed by the authors of this paper and it is intended for use in analyses of linear systems. The impulse response method (in a simpler version) has been already positively verified for such systems by other researchers. In many experimental studies, test systems are often at the threshold of linear operation and nonlinear algorithms are required to describe them effectively. The article presents the results obtained by the method that uses linear approximation applied to the nonlinear system. Despite a strongly nonlinear nature of the system in question and the fact that the computation results of dynamic bearing coefficients are characterized by large standard deviation values, these results have been positively verified by the authors of this article. A nonlinear nature of the tested system manifests itself when a bearing journal travels along a large-sized trajectory and it leads to changes in properties of a lubricating film. The linearization of dynamic coefficients of hydrodynamic bearings operating in nonlinear conditions can cause that results with large errors may be obtained.

The stiffness, damping and mass coefficients were determined for two bearings in one calculation step. A rigid coupling was used to join the two shafts, namely the rotor shaft and the driving motor shaft. In the experiments, the excitations were generated by an impact hammer near the disc located between the bearing supports. It has been found that the coupling has a big impact on the experimental results. The replacement of the rigid coupling by a coupling that will enable damping of torsional vibration may lead to improved results. Due to that fact, bearing no. 2 (i.e. the one situated further from the coupling) should serve as a reference source of information.

In order to verify the experimental results, the numerical model of the mechanical system in question was created using the Abaqus software. The main component of this system was an elastic-damping element, the stiffness and damping characteristics of which were the same as the ones obtained from the experimental tests. The mass of the concentrated mass point was equal to half of the rotor mass. Following the time-domain analysis, it was found that the response signal generated by the numerical model is very similar to the signal measured during the experimental research, which determined that the dynamic coefficients of the hydrodynamic bearings had been correctly determined.

Motivated by the obtained experimental results, the authors also conducted the theoretical analysis. At the present stage of studies, one can positively state that the experimental method for identification of stiffness, damping and mass coefficients can be used at the support points of rotating machinery equipped with two journal slide bearings. The presented method can also be applied to machines operating with other types of bearings (e.g. magnetic or foil bearings). However, one should bear in mind that the method has some limitations that need to be overcome to get it fully operational. During the experimental phase of this method, it is of major importance to minimize the impact of the coupling on the dynamics of a rotating system. Another important aspect is to choose an excitation force in such a way as to produce vibration of a test system and, in addition to this, rotor displacements must be linear. What seems to be problematic is the fact that the results obtained from the real object are widely scattered above and below the means (in other words, they have high standard deviations). For bearings with unknown or very complex geometries, values of their basic dynamic parameters can be successfully identified using the methodology presented herein.

\section{ACKNOWLEDGEMENT}

The research is being financed by the National Science Centre $(\mathrm{NCN})$ in Poland under the research project no. 2015/17/N/ST8/01825. Calculations were carried out at the Academic Computer Centre in Gdańsk.

\section{BIBLIOGRAPHY}

1. Arora, V., Van Der Hoogt, P.J.M., Aarts, R.G.K.M., De Boer, A.: Identification of stiffness and damping characteristics of axial air-foil bearings. International Journal of Mechanics and Materials in Design. 2011, 7(3), pp. 231-243.

2. Bagiński, P., Żywica, G.: Analysis of dynamic compliance of the supporting structure for the prototype of organic Rankine cycle micro-turbine with a capacity of $100 \mathrm{kWe}$. Journal of Vibroengineering. 2016, 18(5), pp. 3153-3163.

3. Błaszczyk, A., Głuch, J., Gardzilewicz, A.: Operating and economic conditions of cooling water control for marine steam turbine condensers. Polish Maritime Research. 2012, 18(3), pp. 48-54.

4. Breńkacz, Ł.: Identification of stiffness, damping and mass coefficients of rotor-bearing system using impulse response method. Journal of Vibroengineering. 2015, 17(5), pp. 2272-2282.

5. Breńkacz, Ł., Żywica, G.: The Sensitivity Analysis of the Method for Identification of Bearing Dynamic Coefficients. In J. Awrejcewicz (Ed.), Dynamical Systems: Modelling: Łódź Poland, December 7-10, 2015. Cham: Springer International Publishing 2016, pp. 81-96.

6. Chatterton, S., Pennacchi, P., Dang, P.V., Vania, A.: Identification Dynamic Force Coefficients of a Five-Pad Tilting-Pad Journal Bearing. In Proceedings of the 9th IFToMM International Conference on Rotor Dynamics. 2015, pp. 931-941. 
7. Dang, P.V., Chatterton, S., Pennacchi, P., Vania, A.: Effect of the load direction on non-nominal five-pad tilting-pad journal bearings. Tribology International. 2016, 98, pp. $197-211$.

8. Delgado, A.: Experimental identification of dynamic force coefficients for a $110 \mathrm{~mm}$ compliantly damped hybrid gas bearing. Journal of Engineering for Gas Turbines and Power. 2015, 137(7), pp. 72502-72502-8.

9. Dimond, T.W., Sheth, P.N., Allaire, P.E., He, M.: Identification methods and test results for tilting pad and fixed geometry journal bearing dynamic coefficients A review. Shock and Vibration. 2009, 16(1), pp. 13-43.

10. Dzida, M., Girtler, J., Dzida, S.: On the possible increasing of efficiency of ship power plant with the system combined of marine Diesel engine, gas turbine and steam turbine in case of main engine cooperation with the gas turbine fed in series and the steam turbine. Polish Maritime Research. 2009, 16(3), pp. 26-31.

11. Jin, J., Wang, Z., Cao, L.: Numerical analysis on the influence of the twisted blade on the aerodynamic performance of thrbine. 2016, 23, pp. 86-90.

12. Kiciński, J.: Dynamics of rotors and slide bearings (in Polish). Gdańsk: IMP PAN, Maszyny Przepływowe 2005.

13. Kiciński, J., Żywica, G.: Steam Microturbines in Distributed Cogeneration. Springer monograph 2014.

14. Kowalczyk, T., Głuch, J., Ziółkowski, P.: Analysis of possible application of high-temperature nuclear reactors to contemporary large-output steam power plants on ships. Polish Maritime Research. 2016, 2(90), pp. 32-41.

15. Kozanecki, Z., Kiciński, J., Żywica, G.: Numerical Model of the High Speed Rotors Supported on Variable Geometry Bearings. In IUTAM Bookseries. 2011, Vol. 1011, pp. 217-227.

16. Litwin, W.: Influence of local bush wear on water lubricated sliding bearing load carrying capacity. Tribology International. 2016, 103, pp. 352-358.

17. Litwin, W., Olszewski, A.: Water-lubricated sintered bronze journal bearings - theoretical and experimental research. Tribology Transactions. 2014, 57(1), pp. 114-122.

18. Paszota, Z.: Losses and energy efficiency of drive motors and systems. Replacement of the Sankey diagram of power decrease in the direction of power flow by a diagram of power increase opposite to the direction of power flow opens a new perspective of research of driv. 2013, 20(1), pp. 3-10.
19. Qiu, Z.L., Tieu, A.K.: Identification of sixteen force coefficients of two journal bearings from impulse responses. Wear. 1997, 212(2), pp. 206-212.

20. Rao, K.R., Kim, D.N., Hwang, J.J.: Fast Fourier Transform - Algorithms and Applications. (Springer, Ed.). Dordrecht 2010.

21. Tiwari, R., Lees, A.W., Friswell, M.I.: Identification of dynamic bearing parameters: a review. The Shock and Vibration Digest. 2004, 36(2), pp. 99-124.

22. Yari, E., Ghassemi, H.: Boundary element method applied to added mass coefficient calculation of the skewed marine propellers. 2016, 23(2), pp. 25-31.

23. Zywica, G., Kicinski, J., Baginski, P.: The static and dynamic numerical analysis of the foil bearing structure. Journal of Vibrational Engineering and Technologies. 2016, 4(3), pp. 213-220.

\section{CONTACT WITH THE AUTHORS}

\section{Łukasz Breńkacz}

Institute of Fluid Flow Machinery

Polish Academy of Sciences

Fiszera 14, 80-231 Gdańsk

Poland 